\title{
The All-Pay Auction with Complete Information and Identity-Dependent Externalities ${ }^{\hbar \pi}$
}

\author{
Bettina Klose \\ Department of Economics, University of Zurich, Blümlisalpstrasse 10, CH-8006 Zurich, Switzerland \\ Dan Kovenock \\ Economic Science Institute, Chapman University, One University Drive, Orange, CA 92866, USA
}

\begin{abstract}
We derive a necessary and sufficient condition for the existence of equilibria with only two active players in the all-pay auction with complete information and identity-dependent externalities. This condition shows that the generic equilibrium of the standard all-pay auction is robust to the introduction of "small" identity-dependent externalities. In general, however, the presence of identity-dependent externalities invalidates well-established qualitative results concerning the set of equilibria of the first-price all-pay auction with complete information. With identity-dependent externalities equilibria are generally not payoff equivalent, and identical players may earn different payoffs in equilibrium. These observations show that Siegel's (2009) results characterizing the set of equilibrium payoffs in all-pay contests, including the all-pay auction as a special case, do not extend to environments with identity-dependent externalities. We further compare the all-pay auction with identity-dependent externalities to the first-price winner-pay auction with identity-dependent externalities. We demonstrate that the equilibrium payoffs of the all-pay auction and winner-pay auction cannot be ranked unambiguously in the presence of identity-dependent externalities by providing examples of environments where equilibrium payoffs in the all-pay auction dominate those in the winner-pay auction and vice versa.
\end{abstract}

Keywords: All-pay auction, Identity-dependent externalities, Payoff nonequivalence, political conflict JEL: D44, D62, D72, C72

\section{Introduction}

The all-pay auction has become a well-established tool for modeling competition in which some scarce resource, such as effort or a monetary bid, is sunk and a prize is won by the player with the highest expenditure (or bid). Given that all players have to pay their bid, a player's losing payoff naturally depends on the bid chosen. In many competitive economic environments, a player also cares about the allocation of the prize in the event that he loses. This phenomenon, known as identity-dependent externalities, has been the focus of an extensive literature in the context of bargaining, mechanism design, and winner-pay auctions. ${ }^{1}$ Jehiel and Moldovanu (2006) survey the literature on winner-pay auctions with externalities and emphasize that equilibrium play in auctions with identity-dependent externalities may differ significantly from behavior in environments without such externalities.

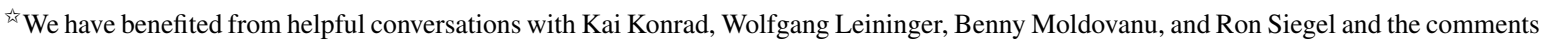
of seminar participants at Chapman University, CORE (Université Catholique de Louvain), Erasmus University Rotterdam, the Max Planck Institute for Tax Law and Public Finance, Mississippi State University, Purdue University, the University of Bonn, the University of California at Riverside, the University of York and the University of Zurich. Earlier versions of this paper were presented at the 2011 Australasian Economic Theory Workshop in Adelaide, the 2011 Meetings of the European Economic Association \& Econometric Society in Oslo, the 2011 Society for the Advancement in Economic Theory Conference in Faro, and the 2012 Conference on Contests, Mechanisms, and Experiments at the University of Exeter. Bettina Klose gratefully acknowledges the financial support of the European Research Council (ERC Advanced Investigator Grant, ESEI-249433) and the Swiss National Science Foundation (SNSF 100014 135257). Dan Kovenock has benefited from the financial support of the Social Science Research Center Berlin (WZB) and the Max Planck Institute for Tax Law and Public Finance in Munich.

Email addresses: bett ina.klose@econ.uzh.ch (Bettina Klose), kovenock@chapman.edu (Dan Kovenock)

${ }^{1}$ See for example das Varma (2002) for an analysis of standard open and sealed bid winner-pay auctions with IDE and Jehiel, Moldovanu, and Stacchetti (1999) or Aseff and Chade (2008) for optimal mechanism design in the presence of identity-dependent externalities. Biran and Forges (2011) show how identity-dependent externalities can explain collusive rings in auctions. The effects of identity-dependent externalities in bargaining and negotiation games are analyzed in Jehiel and Moldovanu (1995a) and Jehiel and Moldovanu (1995b). Jehiel and Moldovanu (1999) and Cornet (2000) consider markets with resale in the presence of identity-dependent externalities.
} 
We show in this paper that equilibria of the all-pay auction with complete information and identity-dependent externalities (henceforth, sometimes abbreviated IDE) generally do not share many of the qualitative properties known to hold for equilibria of the all-pay auction without identity-dependent externalities. For example, it is now well known (see Baye, Kovenock, and de Vries, 1996) that in the standard all-pay auction without IDE there always exists an equilibrium with only two active players and that, generically, this is the unique equilibrium. In the analysis that follows, we prove the existence of equilibrium in all-pay auctions with IDE and provide necessary and sufficient conditions for the existence of equilibria with only two active players (termed,"all-pay auction equilibria"), which yield equilibrium distributions and payoffs to the active players that coincide with the associated standard two-player all-pay auction without IDE. We therefore provide a robustness result, indicating how the results of standard all-pay auctions can be extended to address "small" identity-dependent externalities, and at the same time, specify limits on the nature of identity-dependent externalities that are consistent with the standard analysis. We then provide examples showing both the nonexistence of these "all-pay auction equilibria" and the existence of a multiplicity of such equilibria that are payoff nonequivalent and in which different pairs of players are active. This demonstrates that the payoff equivalence of all equilibria in the standard all-pay auction without IDE, established by Baye et al (1996) does not hold in the presence of identity-dependent externalities. In fact, we show that with IDE, identical players may earn different payoffs.

The payoff nonequivalence of equilibria in all-pay auctions with IDE may appear surprising as Siegel (2009) has demonstrated the generic uniqueness of equilibrium payoffs in all-pay contests that generalize standard all-pay auctions to multiple identical prizes and heterogeneous non-linear costs of bidding and attitudes towards risk. Our results show that the existence of identity-dependent externalities complicates the analysis. Based on our findings, it appears difficult to make statements regarding equilibrium payoffs for environments with identity-dependent externalities that are as strong as those appearing in Baye et al (1996) for standard all-pay auctions or Siegel (2009) for standard all-pay contests with more general cost functions.

The main reason for the variation in equilibrium behavior of a single player in an all-pay auction with IDE is that the value of losing is endogenous and, therefore, a player's willingness to bid depends on all other players' strategies. This phenomenon also arises in winner-pay auctions with IDE. Given the payoff equivalence of the equilibria in the all-pay auction and the undominated strategy equilibria in the winner-pay auction ${ }^{2}$ that arises in environments without IDE (see for instance Morath and Münster, 2008), one might expect a similar relationship between the sets of equilibria in the presence of IDE. We show that this equivalence, in fact, breaks down in environments with IDE. With IDE, equilibrium payoffs cannot be ranked unambiguously. We demonstrate that in the presence of identity-dependent externalities, for some configurations of valuations, there are equilibria in the all-pay auction that payoff dominate all equilibria of the winner-pay auction, while for other configurations there are equilibria of the winner-pay auction that payoff dominate all equilibria of the all-pay auction.

Previous studies of contests with identity-dependent externalities have been few. Contests with IDE employing a lottery contest success function have been examined previously by Linster (1993) and Esteban and Ray (1999). Linster shows that with the lottery contest success function and a constant unit cost of bidding the system of first order conditions for the $n$ players may be solved to derive a Nash equilibrium in pure strategies. He then examines several three-player contests in detail. Esteban and Ray use the lottery contest success function to examine group contests in which groups are heterogeneous and players within a given group are identical. The purpose of their study is to examine how the distribution of individual preferences affects the degree of conflict. Konrad (2006) examines the effect of silent share holdings in an all-pay auction framework in a way that reduces the game to a special case of the all-pay auction with identity-dependent externalities. In his model, only one player ever cares about the identity of the winner in the event of his own loss. Klose and Kovenock (2012) apply the all-pay auction with identity-dependent externalities to examine the role of the distribution of preferences in determining the outcome of conflict over policy. That paper is concerned mainly with three player examples in which player preferences are subject to highly stylized restrictions. Neither of these last two papers examines equilibrium of the all-pay auction with the level of generality found in the current paper. In particular, neither relate the nature of equilibrium to that of equilibria in the absence of IDE or to the winner-pay mechanism.

In section 2 we present the basic model. We summarize the findings regarding equilibria of the winnerpay auction with IDE in section 3. We continue with the analysis of equilibrium payoffs of the all-pay auction with identity-dependent externalities in section 4 and compare the equilibrium payoffs of the all-pay auction and winner-pay auction in section 5. We conclude in section 6.

\footnotetext{
${ }^{2}$ It is well-known that the first-price winner-pay auction does not have an equilibrium in undominated pure strategies. We use the term "undominated strategy equilibrium" to refer to the limit of the pure strategy equilibria in weakly undominated strategies in discrete approximations of the game with a continuous strategy space.
} 


\section{The Model}

Suppose each of a finite set of risk-neutral players $i \in I=\{1, \ldots, n\}$ submits their bid, $x_{i} \in X_{i} \equiv \mathbb{R}_{+}$, for a single prize and the high bidder wins. In case of a relevant tie any procedure may be used to randomly allocate the prize between the high bidders. Winning the prize is worth $v_{i i}$ to player $i$. Players' valuations for losing may depend on the identity of the winner; $v_{i j}$ is the value to player $i$ if player $j$ wins. Player $i$ 's valuation can therefore be represented by an n-dimensional vector $v_{i}=\left(v_{i 1}, v_{i 2}, \ldots, v_{i n}\right)$, whose elements may be positive, negative or zero. The players valuation vectors are common knowledge. If there exists a player $i \in I$ such that $v_{i j} \neq v_{i k}$ for some $j, k \in I \backslash\{i\}$, we say that this auction exhibits identity-dependent externalities. Otherwise, we refer to the game as a standard auction ${ }^{3}$. We consider two distinct auction formats:

1. The first-price winner-pay auction, in which the highest bidder (or that player selected by the tie-breaking rule) wins and the payoff to player $i \in I$ for a given profile of bids, $x=\left(x_{1}, x_{2}, \ldots, x_{n}\right) \in \mathbb{R}_{+}^{n}$, is

$$
u_{i}^{W P}(x)=\left\{\begin{array}{ll}
v_{i i}-x_{i} & \text { if } i \text { wins } \\
v_{i j} & \text { if } j \neq i \text { wins }
\end{array} .\right.
$$

2. The (first-price) all-pay auction, in which all players must pay their bids and the payoff to player $i \in I$ given a profile of bids, $x=\left(x_{1}, x_{2}, \ldots, x_{n}\right) \in \mathbb{R}_{+}^{n}$, is

$$
u_{i}^{A P}(x)=v_{i j}-x_{i}
$$

where $j \in I$ is the highest bidder (or that player selected the winner by the tie-breaking rule).

\subsection{The Reach}

Siegel's (2009) analysis has shown that a fundamental construct when analyzing equilibrium payoffs in (allpay) contests, including the all-pay auction, is the "reach". In the context of a standard all-pay auction his definition of "reach" reduces to the highest bid at which a player's winning payoff is zero.

Definition 1 (Reach, Siegel (2009)). Player i's reach, $r_{i}$, is the highest bid at which his valuation of winning is 0.

In order to make use of this key concept in auctions with IDE, we adapt Siegel's (2009) notion of reach to an environment with IDE as follows:

Definition 2 (Reach in auctions with IDE). Define $r_{i j}=v_{i i}-v_{i j}$ as player $i$ 's reach with respect to player $j$.

Note that player $i$ 's winning payoff when bidding $r_{i j}$ is equal to $v_{i j}$. Therefore, $r_{i j}$ is the maximum that player $i$ would be willing to bid in order to win the prize rather than have player $j$ win. We assume that all players prefer winning to losing. ceteris paribus. ${ }^{4}$

Assumption 1. $v_{i i}>v_{i j}$ for all $i, j \in I$ and $j \neq i$.

Figure 1 illustrates the concept of a player's reach in an all-pay auction with and without IDE. Although a player's payoff contingent on winning still depends only on his bid, when he is affected by IDE, his losing payoff is a function of two variables, his bid and the winner's identity.

\section{Winner-Pay Auctions}

In the first-price winner-pay auction (WPA) the high bidder wins the prize and is the only player who pays his bid. If multiple players tie for the highest bid, then the winner is determined by a pre-specified tie-breaking rule. Therefore, a tie-breaking rule together with the payoff function (1) fully determine the sharing rule $q^{W P}: X \rightarrow \mathbb{R}^{n}$, which selects players' payoffs at every point in the space of pure strategy profiles $X \equiv \times_{i \in I} X_{i}=\mathbb{R}_{+}^{n}$. We refer to this game as $\Gamma^{W P}=\left\{I, \mathbb{R}_{+}^{n}, q^{W P}\right\}$.

The first-price winner-pay auction format is widely applied, and past analyses of standard auctions have focused on the equilibrium in which the player with the highest valuation wins at the second highest valuation.

\footnotetext{
${ }^{3}$ Note that when externalities are identity-independent, i.e. $v_{i j}=v_{i k}$ for all players $i \in I$ and all $j, k \neq i$, a player's valuation only depends on the state of winning or losing the prize, but not on the allocation of the prize given the event that he loses. All of the Baye et al (1996) results, and Siegel's (2009) payoff characterization, apply in this case.

${ }^{4}$ Assumption 1 implies that reaches are strictly positive and thus rules out the existence of a pure strategy equilibrium in which all players bid zero and the outcome is determined by the tie breaking rule.
} 


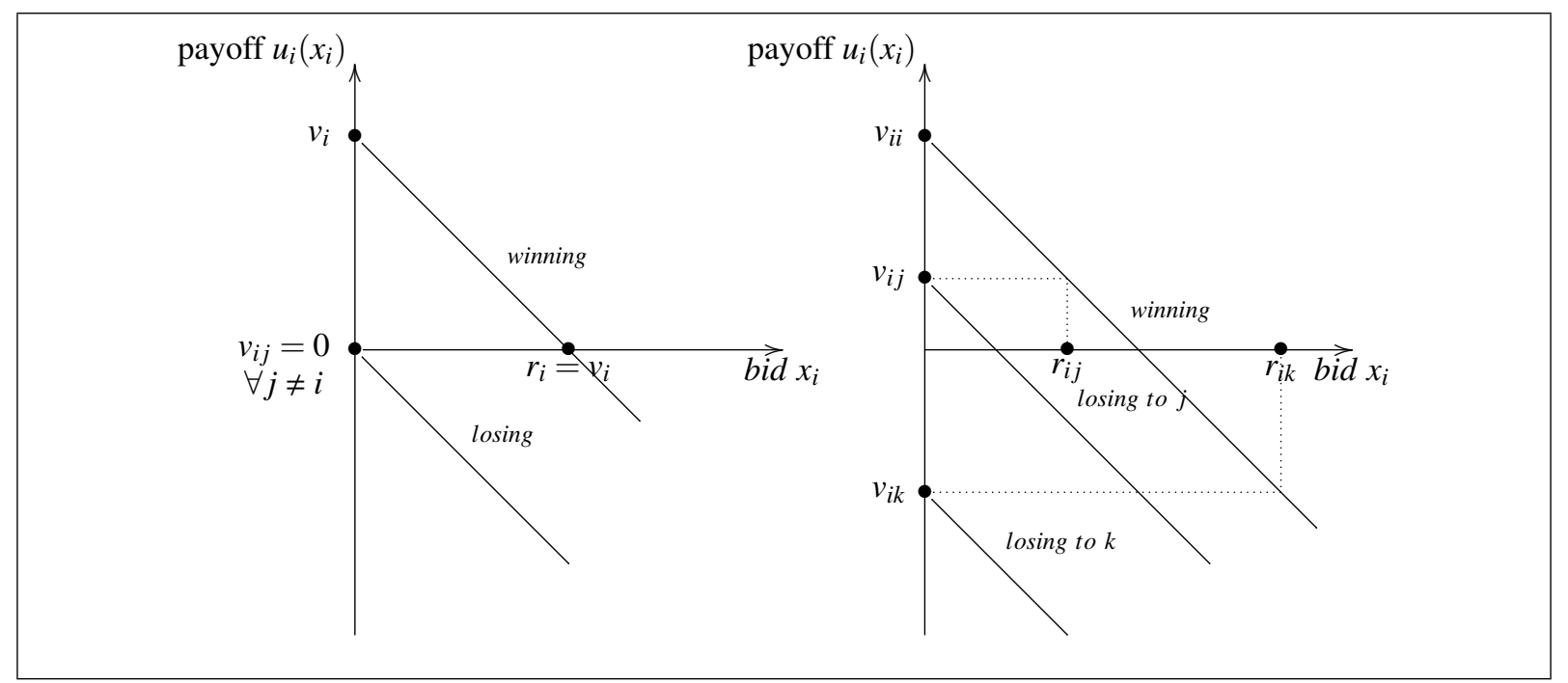

Figure 1: Winning and losing payoff of player $i \in I$ as function of the own bid in an all-pay auction without (left) and with (right) IDE.

This intuitive solution is the unique equilibrium that is the limit of pure strategy equilibria of finite games when the mesh of the grid of the strategy space goes to zero. Albano and Matros (2005) characterize the full set of equilibria, including non-degenerate mixed strategy equilibria.

In many real world applications of the WPA players only care about winning or losing the prize and the price that they pay. On the other hand, one can think of WPAs in which the exact allocation of the prize impacts losing players, for example, because the ownership of the prize will alter future competition between the participants in the auction. Funk (1996), who analyzes equilibria of the WPA with complete information and IDE provides multiple examples, such as the auction of a famous painting, in which a museum that does not obtain the painting will likely prefer to see it going to a private collector rather than another art museum which will potentially attract their visitors. It is therefore not unlikely that bidders in this type of auction may differentiate between their opponents. License auctions such as those for telephone spectrum are another example (see Hoppe, Jehiel, and Moldovanu (2006)). Funk (1996) characterizes the set of pure strategy equilibria of the first-price winnerpay auction with identity-dependent externalities and finds that equilibrium is in general not unique and different equilibria may have different winners and payoffs. Just as in the intuitive equilibrium of the standard winner-pay auction, with IDE the players' reaches determine the equilibrium winners. In order to rule out unrealistic equilibria Funk (1996) also considers "undominated strategy equilibria", that is equilibria in which all players' strategies are in the closure of the set of their undominated strategies. All undominated strategy equilibrium winners and bids of $\Gamma^{W P}$ are characterized in Funk's (1996) Lemma 3:

Theorem 1 (Funk (1996)). The set of undominated strategy equilibrium winners and bids is

$$
\left\{(w, x) \in I \times \mathbf{R}^{n} \mid \forall j \in I: x_{j} \leq r_{j} \text { and } \exists s \neq w: \forall j \neq w, x_{j} \leq x_{s}=x_{w} \in\left[\gamma_{w}, \min \left\{r_{s}, r_{w s}\right\}\right]\right\},
$$

where $r_{i} \equiv \max _{j \in I} r_{i j}$ and $\gamma_{w} \equiv \max _{i \neq w} r_{i w}$.

It follows that a player $i \in I$ is an undominated strategy equilibrium winner if and only if there exists another player $j \in I \backslash\{i\}$ such that the interval $\left[\max _{k \neq i} r_{k i}, \min \left\{r_{j}, r_{i j}\right\}\right]$ is non-empty. Different elements of the set of undominated strategy equilibrium winners and bids may be supported by different tie-breaking rules. In particular, if there exist players $i, j \in I, i \neq j$ such that $r_{i j}=r_{j i} \geq \max \left\{\gamma_{i}, \gamma_{j}\right\}$, then there exist two different deterministic tie breaking rules, one under which $\left(i, r_{i j}\right)$ is in the set of equilibrium winners and winning bids and another one under which $\left(j, r_{i j}\right)$ belongs to this set.

\section{All-Pay Auctions}

In the all-pay auction (APA) players are not reimbursed for their competitive expenditures. Although only a high bidder receives the prize, all bidders pay the cost of their respective bids. As candidates for tie-breaking rules we consider functions that map pure strategy profiles into probability mass functions on the set of high bidders at that point in the space of pure strategy profiles. A tie-breaking rule together with the payoff function (2) define a 
sharing rule $q^{A P}: X \rightarrow \mathbb{R}^{n}$, indicating the payoff to each player at any point in the space of pure strategy profiles. We refer to this game as $\Gamma^{A P}=\left\{I, \mathbb{R}_{+}^{n}, q^{A P}\right\}$. We show in Proposition 1 that the equilibria of the all-pay auction with IDE are not affected by the choice of tie-breaking rule.

The all-pay auction format is used to model competition in which expenditure is sunk and the allocation of the prize is determined by the players' bids only. Prominent examples of competition that satisfy these criteria are lobbying for political rents, research and development races, and job market tournaments. In many of these contests players are not indifferent to the identity of the outcome given that it is not their most preferred one. Lobbyist groups for example typically care about the implemented policy even if it is not their most favored one. Additionally, IDE are often caused by post-auction competitive interactions between the players in which the ownership of the prize plays a role. Imagine three companies which produce imperfect substitute goods. Each company may invest in research in order to develop a new cost saving production technology. In this scenario a company will unlikely be indifferent as to which competitor wins the $R \& D$ race. Not only does it matter which competitor's product is a closer substitute to the company's own product, but also overlap in the targeted consumer markets or possible licensing agreements (among other factors) make players discriminate between their opponents.

Baye et al (1996) provide a complete characterization of the set of equilibria for the standard n-player all-pay auction with complete information. They show that the equilibrium is only unique when the third highest reach is strictly smaller than the second highest. Otherwise, multiple equilibria arise, which are payoff equivalent but may yield different revenues. The equilibrium in which the two players with the highest reaches randomize their bids together over the interval between zero and the second highest reach and all other players stay out of the competition by bidding zero has attracted the most attention. This is the unique equilibrium in the case that the two highest reaches are uniquely identified, and an equilibrium of this type still exists in all other cases of the standard all-pay auction.

The main focus of this section is to show the existence of a certain type of equilibrium in the presence of IDE that shares several of the properties of the equilibria with two active players identified by Baye et al (1996). Alcalde and Dahm (2010) define an "all-pay auction equilibrium" as an equilibrium in which only two players with the highest valuations, $v_{1}$ and $v_{2}$ (with $v_{1} \geq v_{2}$ ), actively participate (i.e., place positive bids with positive probability), their expected bids are $v_{2} / 2$ and $\left(v_{2}\right)^{2} /\left(2 v_{1}\right)$, and expected payoffs are $v_{1}-v_{2}$ and 0 , respectively. Alcalde and Dahm's (2010) analysis shows that contests in which players pay their own bids exhibit this type of equilibrium under a wide class of contest success functions satisfying a set of conditions, which include monotonicity and anonymity properties, restrictions on the set of discontinuities, and an elasticity property which implies that, conditional on the profile of bids, the highest bidder is sufficiently likely to win the contest.

Siegel (2009) keeps the assumption of an auction contest success function (i.e. the high bidder wins the prize with certainty) and shows, under fairly general assumptions on a player's payoffs from winning and losing as a function of his own bid, ${ }^{5}$ that there always exists an equilibrium in which all players receive the "all-pay auction equilibrium" payoffs, that is the maximum of their power ${ }^{6}$ and zero. Siegel's (2009) Theorem 1 states that in generic ${ }^{7}$ all-pay contests of this type all equilibria are payoff equivalent with exactly the payoff structure described above. ${ }^{8}$

Any of these observations may be violated when IDE are present. Throughout our analysis we will refer to equilibria in the mixed extension of the game $\Gamma^{A P}=\left\{I, \mathbb{R}_{+}^{n}, q^{A P}\right\}$ with the set of players $I$, pure strategy sets $X_{i}=\mathbb{R}_{+}$and sharing rule $q^{A P}$ based on a tie-breaking rule and payoff functions $u_{i}^{A P}(x), i \in I$, given in (2). We alternately denote a strategy of player $i$ in the mixed extension of $\Gamma^{A P}$ by the probability measure on $\mathbb{R}_{+}, \mu_{i}$, or the corresponding cumulative distribution function $F_{i}$. Adapting the reasoning of Alcalde and Dahm (2010) to the case of IDE, we may modify the definition of an all-pay auction equilibrium for this case.

Definition 3 (All-pay Auction Equilibrium with IDE). In an all-pay auction equilibrium $F^{*}=\left(F_{1}^{*}, F_{2}^{*}, \ldots, F_{n}^{*}\right)$ only two bidders, $i$ and $j$, submit strictly positive bids with positive probability. All other bidders abstain from the contest (by bidding zero). With $r_{i j} \geq r_{j i}$ the expected bid of player $i$ is $E\left(F_{i}^{*}\right)=r_{j i} / 2$ and the expected bid of $j$ is $E\left(F_{j}^{*}\right)=\left(r_{j i}\right)^{2} /\left(2 r_{i j}\right)$. Player $i$ 's expected equilibrium payoff is $v_{i i}-r_{j i}$, player $j$ 's expected equilibrium payoff is $v_{j i}$.

\footnotetext{
${ }^{5}$ These assumptions include the all-pay auction as a special case.

${ }^{6}$ When constrained to the special case of the single-prize all-pay auction, in Siegel's (2009) terminology the power of a player is his valuation of winning at the second highest reach (see Definition 1).

${ }^{7}$ In the context of a single-prize all-pay contest Siegel's (2009) notion of generic refers to the case that (i) only one player has power 0 and (ii) this player's valuation of winning is strictly decreasing at his reach. Note that the second condition is always satisfied in all-pay auctions where the cost is equal to the bid.

${ }^{8}$ Although, because of the use of general cost functions, neither Alcalde and Dahm's (2010) condition that only two active bidders participate nor their condition on the expected bid of each player necessarily hold in the equilibria identified by Siegel (2009).
} 
In this definition we do not pin down the identity of the two active players because, as we show in section 4.1, in environments with IDE there may exist all-pay auction equilibria in which the two players who are active have reaches with respect to one another that are small relative to the reaches of other pairs of players.

In section 4.1 we demonstrate that in the presence of IDE all-pay auction equilibria need not exist. In fact, we provide a necessary and sufficient condition for the existence of such an equilibrium. Before doing so, we first apply a result due to Simon and Zame (1990) to show that in the complete information all-pay auction with IDE a mixed-strategy equilibrium always exists. The first step is to apply their main theorem to show that there exists a profile of mixed strategies, $\mu=\left(\mu_{1}, \ldots, \mu_{n}\right)$, and an endogenously determined sharing rule, ${ }^{9} q$, such that $\mu$ is a Nash equilibrium if relevant ties are broken according to the sharing rule $q$. Following the logic of the "Tie Lemma" in Siegel (2009), we then show that no relevant ties occur in equilibrium and, as a consequence, $\mu$ is a Nash equilibrium of the all-pay auction even when other sharing rules are applied. ${ }^{10}$

Proposition 1 (Existence). Every complete information all-pay auction with identity-dependent externalities, $\Gamma^{A P}$, has a Nash equilibrium in mixed strategies.

Proof. For every player $i \in I$ define $r_{i}=\max _{j \in I} r_{i j}$. Then, by definition of $r_{i}$, player $i \in I$ would prefer losing to any of his opponents over winning with a bid that is higher than $r_{i}$, i.e. all bids which are strictly greater than $r_{i}$ are strictly dominated by bidding zero. Therefore, we restrict player $i$ 's, $i \in I$, strategy space in this proof to $X_{i}=\left[0, r_{i}\right]$, which is compact in $\mathbb{R}_{+}$. Let $X=X_{1} \times X_{2} \times \cdots \times X_{n}$ and $X^{*}=\left\{x \in X \mid \exists i \in I: x_{i}>x_{j} \quad \forall j \in I \backslash\{i\}\right\}$, then $X^{*}$ is a dense subset of $X$. Define the bounded and continuous payoff function $\varphi: X^{*} \rightarrow \mathbb{R}^{n}$ by

$$
\varphi(x)=\left(v_{1 w}-x_{1}, v_{2 w}-x_{2}, \ldots, v_{n w}-x_{n}\right),
$$

where $w=\arg \max _{i \in I} x_{i}$.

Let $C_{\varphi}: X \rightarrow \mathbb{R}^{n}$ be the correspondence whose graph is the closure of the graph of $\varphi$, and define $Q_{\varphi}(x)$ to be the convex hull of $C_{\varphi}(x)$ for each $x \in X$. Let $W(x)=\left\{i \in I \mid x_{i}=\max _{j \in I} x_{j}\right\}$. Then $W(x)$ and $Q_{\varphi}(x)$ are singletons for $x \in X^{*}$. For $x \in X \backslash X^{*}$

$$
Q_{\varphi}(x)=\left\{\sum_{i \in W(x)} \alpha_{i}\left(v_{1 i}-x_{1}, \ldots, v_{n i}-x_{n}\right) \mid \alpha_{i} \in[0,1] \quad \forall i \in W(x), \sum_{i \in W(x)} \alpha_{i}=1\right\} .
$$

$Q_{\varphi}$ is bounded and upper hemi-continuous, with nonempty, convex, compact values and coincides with $\varphi$ on $X^{*}$. Then from Simon and Zame (1990) there exists a Borel measurable function $q=\left(q_{1} \ldots, q_{n}\right): X \rightarrow \mathbb{R}^{n}$ with $q(x) \in Q_{\varphi}(x)$ for all $x \in X$ and a profile of mixed strategies $\mu=\left(\mu_{1}, \ldots, \mu_{n}\right)$, where $\mu_{i}$ is a probability measure on $X_{i}, i \in I$, such that for each player $i \in I$

$$
\int_{X} q_{i}(x) d \mu \geq \int_{X} q_{i}(x) d\left(\beta_{i} \times \mu_{-i}\right)
$$

for all probability measures $\beta_{i}$ on $X_{i}$. That is $\mu$ is a Nash equilibrium when ties are broken as specified by $q$. Next, following the argument of Siegel (2009), we show that $\mu\left(X \backslash X^{*}\right) \equiv \int_{X \backslash X^{*}} d \mu(x)=0$; hence $\mu$ constitutes a Nash equilibrium for any sharing rule $\tilde{q}$ with $\tilde{q}(x) \in Q_{\varphi}(x)$, for all $x \in X$. By way of contradiction, assume that there exists a subset of players $N \subseteq I$, with $|N| \geq 2$, who have an atom at some $b \in \bigcap_{i \in N} X_{i}$, such that $\mu\left(\left\{x \in X \mid x_{i}=b \quad \forall i \in N, x_{i}<b \quad \forall i \in I \backslash N\right\}\right)>0$. Then, there exists at least one player $i \in N$ who can strictly increase his probability of winning by moving his atom at $b$ to a slightly higher bid. By assumption $1, i$ would be strictly better off if this bid is sufficiently close to $b$, contradicting that $\mu_{i}$ is a best-response for player $i$. This shows that $\mu\left(X \backslash X^{*}\right)=0$ and $\mu$ is a Nash equilibrium for any sharing rule $\tilde{q}$.

\footnotetext{
${ }^{9}$ In the case of the all-pay auction with IDE, the sharing rule is already uniquely determined for all strategy profiles which exhibit a unique highest bid. The part of the sharing rule, which will be determined endogenously is concerned with ties. Therefore, we can say that in the game $\Gamma^{A P}$ Simon and Zame's (1990) result shows that an endogenously determined tie-breaking rule exists, such that an equilibrium in mixed strategies exists in the game with this tie-breaking rule.

${ }^{10} \mathrm{~A}$ number of other results in the literature on existence of equilibria in discontinuous games can be applied, although verification that the stated sufficient conditions are satisfied is sometimes taxing. For instance, with considerable work, one may show that the finite deviation property holds in the mixed extension of the all-pay auction with identity-dependent externalities, so that Theorem 2.9 of Reny (2009) applies. It is useful to note, however, that several existence theorems appearing in the literature, which cite the standard all-pay auction as an example of the theorem's applicability, do not apply generally to all-pay auctions with identity-dependent externalities. For example, neither the uniform payoff security condition of Monteiro and Page Jr (2007) nor the hospitality condition of Prokopovych and Yannelis (2013) apply generally to all-pay auctions with identity-dependent externalities.
} 


\section{1. (Non-)Existence of an All-Pay Auction Equilibrium}

An all-pay auction equilibrium exists if and only if there exists a pair of players such that no other player is willing to submit any positive bid when these two players compete against each other in a two-player all-pay auction.

Proposition 2 (Necessary and Sufficient Condition for the Existence of an "All-Pay Auction Equilibrium"). There exists an equilibrium in which player $i$ employs the mixed strategy

$$
F_{i}(x)=\left\{\begin{array}{cl}
0 & \text { if } x<0 \\
\frac{x}{r_{j i}} & \text { if } 0 \leq x \leq r_{j i} \\
1 & \text { if } x>r_{j i}
\end{array}\right.
$$

player $j$ employs the mixed strategy

$$
F_{j}(x)=\left\{\begin{array}{cl}
0 & \text { if } x<0 \\
\left(1-\frac{r_{j i}}{r_{i j}}\right)+\frac{x}{r_{i j}} & \text { if } 0 \leq x \leq r_{j i} \\
1 & \text { if } x>r_{j i}
\end{array}\right.
$$

and all other players bid zero with certainty (i.e. $F_{k}(x)=1 \forall x \geq 0$ ) if and only if

$$
r_{i j} \geq r_{j i} \geq\left(1-\frac{r_{j i}}{2 r_{i j}}\right) r_{k i}+\frac{r_{j i}}{2 r_{i j}} r_{k j}
$$

for all $k \in I \backslash\{i, j\}$.

Before proceeding with the proof, note that the logic of the characterization of equilibrium with two players in the standard all-pay auction (Hillman and Riley, 1989) implies that if an all-pay auction equilibrium exists with players $i$ and $j$ the only active players and $r_{i j} \geq r_{j i}$, then the equilibrium requires that these two players randomize according to the distributions defined in the proposition. Similarly, if distributions defined in the proposition form an equilibrium, then $r_{i j} \geq r_{j i}$ and the equilibrium is an "all-pay auction equilibrium."

Proof. " $\longrightarrow$ "Suppose the strategies specified in the proposition form an equilibrium. Then the probability that player $i$ wins the auction is $\left(1-\frac{r_{j i}}{2 r_{i j}}\right)$ and the probability that player $j$ wins is $\frac{r_{j i}}{2 r_{i j}}$. Therefore, each player $k \in I \backslash\{i, j\}$ earns an expected payoff of $\left(1-\frac{r_{j i}}{2 r_{i j}}\right) v_{k i}+\frac{r_{j i}}{2 r_{i j}} v_{k j}$. Because the given strategies form an equilibrium, no player $k \in I \backslash\{i, j\}$ is able to profitably deviate to a bid $x \geq r_{j i}$ and win with certainty. Consequently, for such an $x, v_{k k}-x \leq\left(1-\frac{r_{j i}}{2 r_{i j}}\right) v_{k i}+\frac{r_{j i}}{2 r_{i j}} v_{k j}$, which implies that $\left(1-\frac{r_{j i}}{2 r_{i j}}\right) r_{k i}+\frac{r_{j i}}{2 r_{i j}} r_{k j} \leq x$. Since this holds for all $x \geq r_{j i}$, it follows that $r_{i j} \geq r_{j i} \geq\left(1-\frac{r_{j i}}{2 r_{i j}}\right) r_{k i}+\frac{r_{j i}}{2 r_{i j}} r_{k j}$.

" $\longleftarrow$ "Suppose (3) holds. If players $k \in I \backslash\{i, j\}$ bid zero with certainty, then it follows from Hillman and Riley (1989) that the given strategies for players $i$ and $j$ constitute best responses. So it is sufficient to prove that no player $k \in I \backslash\{i, j\}$ has a profitable deviation. Suppose such a player $k$ submits a bid $x \geq r_{j i}$. Then, he would win with certainty and his payoff would be

$$
v_{k k}-x \leq v_{k k}-r_{j i} \leq v_{k k}-\left[\frac{r_{j i}}{2 r_{i j}} r_{k j}+\left(1-\frac{r_{j i}}{2 r_{i j}}\right) r_{k i}\right]=\frac{r_{j i}}{2 r_{i j}} v_{k j}+\left(1-\frac{r_{j i}}{2 r_{i j}}\right) v_{k i} .
$$

If player $k$ submits a bid $x \in\left(0, r_{j i}\right)$, then his expected payoff is

$$
\begin{aligned}
u_{k}\left(x, F_{-k}\right)= & -x+v_{k k} F_{i}(x) F_{j}(x)+v_{k i} F_{j}(x)\left(1-F_{i}(x)\right)+v_{k j} F_{i}(x)\left(1-F_{j}(x)\right) \\
& +v_{k i} \int_{x}^{r_{j i}}\left(1-F_{i}(s)\right) f_{j}(s) d s+v_{k j} \int_{x}^{r_{i j}}\left(1-F_{j}(s)\right) f_{i}(s) d s \\
= & \frac{r_{j i}}{2 r_{i j}} v_{k j}+\left(1-\frac{r_{j i}}{2 r_{i j}}\right) v_{k i}-x\left[1-\left(r_{k i} \frac{x+2 r_{i j}-2 r_{j i}}{2 r_{i j} r_{j i}}+r_{k j} \frac{x}{2 r_{i j} r_{j i}}\right)\right] \\
< & \frac{r_{j i}}{2 r_{i j}} v_{k j}+\left(1-\frac{r_{j i}}{2 r_{i j}}\right) v_{k i},
\end{aligned}
$$

where the final inequality follows from (3). Consequently, no profitable deviation exists and the given strategy profile constitutes an all-pay auction equilibrium. 
Proposition 2 proves that all-pay auction equilibria may exist in the presence of identity-dependent externalities. Moreover, it illustrates that a player's willingness to bid is endogenous: the maximum bid at which player $k$ 's, $k \in I \backslash\{i, j\}$, payoff from winning is at least as high as his payoff from losing with a bid of zero depends on other players' probabilities of winning (and, therefore, their strategies). More specifically, this maximum bid is equal to the convex combination of his reaches with respect to the two active players, using the active players' respective winning probabilities as weights. One consequence is that the condition for the existence of an all-pay auction equilibrium is trivially satisfied whenever there exist an $i$ and $j$ such that each of the players $k \in I \backslash\{i, j\}$ is not willing to bid more against either $i$ or $j$ than $i$ and $j$ are willing to bid against each other $\left(r_{k i}, r_{k j} \leq \min \left\{r_{i j}, r_{j i}\right\}\right.$ $\forall k \in I \backslash\{i, j\})$.

A direct implication of this condition is that all-pay auctions with identity-dependent externalities that are sufficiently close to a "generic" standard all-pay auction without such externalities will possess an equilibrium qualitatively similar to that of the standard auction (in this case to be "generic" it is sufficient that in the standard all-pay auction there is a strict ordering between the three highest values of winning). For instance if for every $i \in I, v_{i j}$ is close to being constant across $j \neq i$ (such as, but not restricted to, $v_{i j} \approx 0$ for all $j \in I \backslash\{i\}$ ), then $r_{i j} \equiv v_{i i}-v_{i j}$ is for every $j \in I \backslash\{i\}$ close to a constant, which we will call $r^{i}$. In this case, if the largest three $r^{i}$,s are strictly ranked, say $r^{1}>r^{2}>r^{3} \geq \ldots \geq r^{n}$, in such a way that $r_{1 j}>r_{2 k}>r_{l m}$ for every $j \neq 1, k \neq 2, l \notin\{1,2\}$, and $m \in I$, then there exists an equilibrium of the all-pay auction with identity-dependent externalities that is qualitatively similar to that of the standard all-pay auction with values $v_{i}=r^{i}$. In this equilibrium only players 1 and 2 are active, with player 2 placing a mass point at zero. Thus, Proposition 2 provides, as a special case, a robustness result indicating how the results of standard all-pay auctions can be extended to address "small" identity-dependent externalities.

Another implication of the condition is that a sufficient condition for the existence of an all-pay auction equilibrium is that $d(i, j) \equiv r_{i j}$ is a semi-metric. ${ }^{11}$ In this case, $r_{i j}=r_{j i}$ for every $i, j \in I$, and the existence of a pair $i, j \in\left\{\arg \max _{l, m \in I} r_{l m}\right\}$ guarantees that $r_{k i}, r_{k j} \leq \min \left\{r_{i j}, r_{j i}\right\} \forall k \in I \backslash\{i, j\}$.

Note that Proposition 2 does not preclude the possibility of the existence of multiple all-pay auction equilibria The case in which there are three players and $r_{i j}, i, j \in I$ is a semi-metric provides a useful example.

Example 1 (Multiplicity of All-Pay Auction Equilibria). Let $I=\{1,2,3\}$ and assume that $r_{i j}, i, j \in I$, is a semimetric. Without loss of generality label players so that $r_{12}=r_{21} \equiv r^{\max } \geq r_{13}=r_{31} \equiv r^{\text {med }} \geq r_{23}=r_{32} \equiv r^{\text {min }}$ (see Figure 2). Clearly, $r_{12}=r_{21} \geq\left(1-\frac{r_{21}}{2 r_{12}}\right) r_{31}+\frac{r_{21}}{2 r_{12}} r_{32}=\frac{1}{2} r_{31}+\frac{1}{2} r_{32}$, so, from Proposition 2 , an all-pay auction

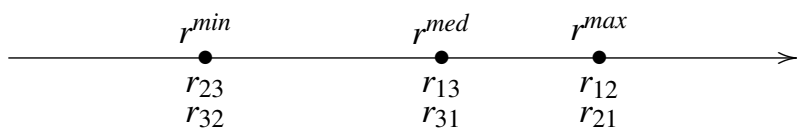

Figure 2: Illustration of a configuration of reaches in a three player environment that leads to the existence of multiple all-pay auction equilibria

equilibrium exists with players 1 and 2 the active players and player 3 bidding zero with certainty. Examining the common reach of players 1 and 3 with respect to one another, the necessary and sufficient condition from Proposition 2 for these two players to to be the sole active players in an all-pay auction equilibrium is $r_{13}=r_{31} \geq$ $\left(1-\frac{r_{31}}{2 r_{13}}\right) r_{21}+\frac{r_{31}}{2 r_{13}} r_{23}=\frac{1}{2} r_{21}+\frac{1}{2} r_{23}$. So as long as this condition holds, that is, $r^{\text {med }} \geq \frac{1}{2} r^{\max }+\frac{1}{2} r^{\min }$, there exists an all-pay auction equilibrium in which players 1 and 3 are active and player 2 bids zero with certainty. If $r^{\text {med }}<$ $\frac{1}{2} r^{\max }+\frac{1}{2} r^{\min }$ then no such equilibrium exists. Finally, the necessary and sufficient condition for players 2 and 3 to be the sole active players in an all-pay auction equilibrium is $r^{\min } \equiv r_{23}=r_{32} \geq \frac{1}{2} r_{12}+\frac{1}{2} r_{13}=\frac{1}{2} r^{\max }+\frac{1}{2} r^{\text {med }}$. Clearly, this holds if and only if $r^{\max }=r^{\text {med }}=r^{\mathrm{min}}$.

Our next example shows that, even in simple three player environments with identity-dependent externalities, an all-pay auction equilibrium does not necessarily exist. It therefore illustrates the "only if" part of Proposition 2. This stands in contrast with the results of Baye et al (1996), which demonstrate the existence of an all-pay auction equilibrium in standard all-pay auctions for any configuration of player values of the prize.

Example 2 (Non-Existence of an All-pay Auction Equilibrium). Consider an APA with three players in which players may differ in their valuations of winning the prize, but agree as to how much they would each be willing

\footnotetext{
${ }^{11}$ As a semi-metric $d(i, j) \equiv r_{i j}$ is required to satisfy non-negativity, identity of indiscernables $\left(r_{i j}=0\right.$ if and only if $\left.i=j\right)$, and symmetry $\left(r_{i j}=r_{j i}\right)$. It is not required to satisfy the triangle inequality. Note that, from Assumption 1, the first two conditions are always satisfied.
} 
to spend in order to outbid a common opponent, e.g. valuations are distributed such that $r_{21}=r_{31}<r_{12}=r_{32}<$ $r_{13}=r_{23}$ (see Figure 3).

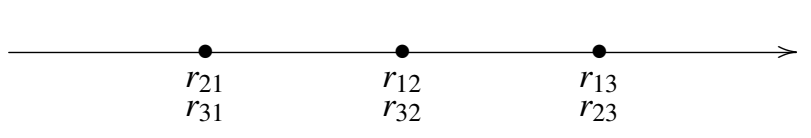

Figure 3: Illustration of a configuration of reaches in a three player environment that leads to the nonexistence of all-pay auction equilibrium.

Clearly in this example no player ever stays out of the contest, i.e. bids zero with certainty, in equilibrium. If player $i \in I=\{1,2,3\}$ bids zero, then the remaining two players $j$ and $k, j, k \in I \backslash\{i\}, j \neq k$ must randomize continuously up to $\min \left\{r_{j k}, r_{k j}\right\}$. As a consequence, both, $j$ and $k$ win with positive probability. Therefore, there exists a bid $x \in\left(\min \left\{r_{j k}, r_{k j}\right\}, \max \left\{r_{j k}, r_{k j}\right\}\right)$ such that player $i$ 's payoff when bidding zero is equal to his payoff when winning at $x$. However, because players $j$ and $k$ do not submit bids higher than $\min \left\{r_{j k}, r_{k j}\right\}$, player $i$ could increase his payoff by outbidding the other players with certainty. The interval $\left(\min \left\{r_{j k}, r_{k j}\right\}, x\right)$ is nonempty and any bid in that interval strictly increases player i's payoff. Therefore, in equilibrium $i$ cannot stay out of the contest.

Note that this example is robust in the sense that there is an open set of vectors of reaches, which contains the vector employed in the example, for which the conditions of Proposition 2 do not hold. Thus, the existence of an all-pay auction equilibrium is not a generic property in all-pay auctions with IDE.

\subsection{Equilibrium Payoffs}

Baye et al (1996) show for the standard all-pay auction that even if multiple equilibria exist, they are all payoff equivalent. In the same spirit, Siegel's (2009) main result uniquely determines all players' equilibrium payoffs in generic contests, implying that equilibria of all-pay contests are generically payoff equivalent. In the following, using a simple example, we show that (i) players' payoffs may vary across equilibria, and (ii) identical players may earn different payoffs in the all-pay auction with identity-dependent externalities. We start by demonstrating both claims with an example in which identical players earn different equilibrium payoffs. We then argue that this example may be extended to an open set of vectors of reaches for which multiple equilibria exist and players' payoffs vary across equilibria.

Example 3 (Different Payoffs to Identical Players). Consider an environment with three players and the following order of reaches ${ }^{12}: r_{12}=r_{21}<r_{13}=r_{23}<r_{31}=r_{32}$ (see Figure 4). Note that players 1 and 2 are identical.

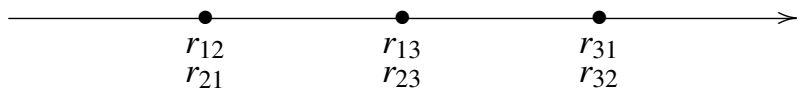

Figure 4: Illustration of a configuration of reaches that leads to different equilibrium payoffs for identical players.

In this example players 1 and 2 may choose identical strategies, in which case the (symmetric) equilibrium strategy profile is the following: Let $j, k \in\{1,2\}, j \neq k$,

$$
\begin{gathered}
F_{j}(x)=\left\{\begin{array}{cl}
0 & \text { if } x<0 \\
{\left[\left(1-\frac{\bar{s}}{r_{3 j}}\right)+\frac{x}{r_{3 j}}\right]^{\frac{1}{2}}} & \text { if } 0 \leq x \leq \bar{s}, \\
1 & \text { if } x>\bar{x}
\end{array}\right. \\
F_{3}(x)=\kappa F_{j}(x)-(\kappa-1) F_{j}(x)^{-\frac{r_{j k}}{r_{j 3}}}
\end{gathered}
$$

with $\kappa=\frac{2 r_{j 3}}{r_{j 3}+r_{j k}}>1$ and $\bar{s}=r_{j 3}\left[1-\left(1-\frac{1}{\kappa}\right)^{\kappa}\right]$. Note that $\bar{s} \in\left(r_{j k}, r_{j 3}\right)$. is the upper bound of the support of each of the three players' equilibrium strategies.

\footnotetext{
${ }^{12}$ A similar configuration of reaches is examined in Klose and Kovenock's (2012) analysis of extremism and moderation, representing the case of two centrist players and one radical.
} 
There also exist equilibria, which take on the "all-pay auction equilibrium" form, i.e. one player, $i \in\{1,2\}$, does not participate in the all-pay auction and free rides. The other two players randomize together up to $r_{j 3}, j \in$ $\{1,2\} \backslash\{i\}$. Their equilibrium strategies are:

$$
\begin{gathered}
F_{i}(x)=\left\{\begin{array}{ll}
0 & \text { if } x<0 \\
1 & \text { if } x \geq 0
\end{array},\right. \\
F_{j}(x)=\left\{\begin{array}{cc}
0 & \text { if } x<0 \\
\left(1-\frac{r_{j 3}}{r_{3 j}}\right)+\frac{x}{r_{3 j}} & \text { if } 0 \leq x \leq r_{j 3} \\
1 & \text { if } x>r_{j 3}
\end{array},\right. \\
F_{3}(x)=\left\{\begin{array}{cc}
0 & \text { if } x<0 \\
\frac{x}{r_{j 3}} & \text { if } 0 \leq x \leq r_{j 3} . \\
1 & \text { if } x>r_{j 3}
\end{array}\right.
\end{gathered}
$$

In this equilibrium the free riding player, $i$, receives a payoff $u_{i}^{*} \in\left(v_{i 3}, v_{i j}\right)$, which is strictly greater than the payoff that the ex-ante identical player $j \in\{1,2\} \backslash\{i\}$ receives, $u_{j}^{*}=v_{i 3}$.

Several comments are in order. First note that by Theorem 1 identical players may also earn different equilibrium payoffs in the winner-pay auction. We examine further the comparison of the all-pay auction with the winner-pay auction in section 5.

The (asymmetric) all-pay auction equilibria in which either player 1 or 2 abstains from the contest clearly persist if we perturb the environment slightly. Two infinitesimally different players earn strictly different payoffs in this equilibrium. The existence of an open set of vectors of reaches for which equilibria are not payoff equivalent shows that it is not possible to generalize Siegel's (2009) characterization of equilibrium payoffs to contests with IDE, even if one restricts the cost functions to the most simple form as used in the all-pay auction.

\section{Comparison of Equilibria}

We have shown in the previous section that equilibria of the APA with IDE do not share many of the features of the equilibria of the standard all-pay auction or do so only under strong restrictions on players' valuations. Below we show that although there exists a strong connection between the equilibrium payoffs of standard winner-pay and all-pay auctions the same cannot be said about these auction formats in the presence of identity-dependent externalities.

From the equilibrium characterization in Baye et al (1996) we know that in the standard all-pay auction all players earn the maximum of their power and zero in any equilibrium. It is easy to see that the same is true for the undominated pure strategy equilibria of the standard winner-pay auction (see footnote 2), as players' reaches here are just their respective valuations of the prize and a player with the highest valuation wins at the second highest valuation.

Funk (1996) shows that undominated strategy equilibria of the WPA with IDE are in general not payoff equivalent, and that multiple equilibria may exhibit different winners. We have found the same true for APA with IDE, therefore it is not digressive to ask whether for every equilibrium there exists an equilibrium of the winner-pay auction whose payoffs coincide with those of an equilibrium of the all-pay auction. Below we show that in the presence of IDE the two auction formats considered cannot generally be ranked by their equilibrium payoffs.

Example 4 (Higher Payoffs in the All-Pay Auction). Example 3 provides a configuration of valuations for which there exists an equilibrium of the all-pay auction with identity-dependent externalities that strictly payoff dominates any undominated strategy equilibrium of the winner-pay auction (see Figure 5).

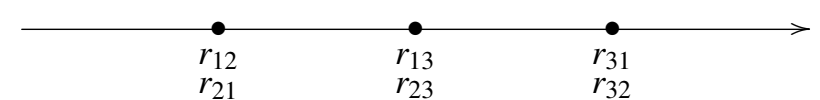

Figure 5: Illustration of a configuration of reaches that leads to higher equilibrium payoffs in the all-pay auction than in the winner-pay auction.

In that example, we identify an equilibrium mixed-strategy profile of the all-pay auction in which identical players play identical strategies and the payoff to each player $i$ is $v_{i i}-\bar{s}$, where $\bar{s} \in\left(r_{j k}, r_{j 3}\right), j, k \in\{1,2\}, j \neq k$, is 
the common upper bound of the support of the three players' strategies. In the corresponding winner-pay auction any undominated strategy equilibrium yields a unique winner, player 3 , at a unique winning bid equal to $r_{13}=r_{23}$. Therefore, any winner-pay equilibrium yields a payoff $v_{i 3}$ to players $i \in\{1,2\}$ and $v_{33}-r_{i 3}$ to player 3 .Clearly, since $\bar{s}<r_{13}=r_{23}$, every player earns a strictly higher payoff in the equilibrium of the all-pay auction.

In Example 3 we also identify two all-pay auction equilibria in which either player 1 or 2 bid zero with probability one and the other two players randomize up to $r_{13}=r_{23}$. In both of these equilibria, the inactive player receives a strictly higher payoff than in the winner-pay auction, and the two active players receive the same payoff in both auctions. In fact, for the indicated configuration of values, every equilibrium of the APA must have at least one player do strictly better than the payoff in the winner-pay equilibrium in undominated strategies and no player do worse. This is true since for both players 1 and 2 , any bid above $r_{13}=r_{23}$ is strictly dominated by bidding zero, hence no equilibrium of the all-pay auction can give any player a strictly lower expected payoff than in the winner-pay auction. Furthermore, in any equilibrium at least one of the players $i \in\{1,2\}$ must win with positive probability and the other player $(j \in\{1,2\} \backslash\{i\})$ must earn strictly greater than $v_{j 3}$, since he always has the opportunity to respond by bidding zero and earning $v_{j i}$ with positive probability and $v_{j 3}$ with the remaining probability.

Although, in the environment above, in every equilibrium of the APA all players' payoffs are at least as high and at least one player's payoff strictly higher than the respective payoffs in undominated strategy equilibria of the WPA, we show below that this ranking is not universal. There also exist environments in which there is an undominated pure strategy equilibrium of the winner-pay auction that yields strictly higher payoffs to all players than any equilibrium of the all-pay auction.

Example 5 (Higher Payoffs in the Winner-Pay Auction). Consider an all-pay auction with three players and the following order of reaches: $r_{13}=r_{23} \leq r_{31}=r_{32} \leq r_{12}=r_{21}$ (see Figure 6).

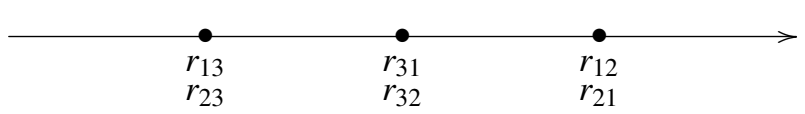

Figure 6: Illustration of a configuration of reaches that leads to higher equilibrium payoffs in the winner-pay auction than in the all-pay auction.

There exist multiple undominated strategy equilibria of the winner-pay auction in this environment.

1. Player $i \in\{1,2\}$ may win at $r_{i j}, j \in\{1,2\} \backslash\{i\}$, in which case player 3 receives $v_{3 i}$, player $j$ receives $v_{j i}$ and the winner $i$ receives $v_{i i}-r_{i j}=v_{i j}$.

2. Player 3 may win at a bid $x \in\left[r_{i 3}, r_{3 i}\right], i \in\{1,2\}$, in which case he earns $v_{33}-x \in\left[v_{33}-r_{3 i}, v_{33}-r_{i 3}\right]$ and players $i \in\{1,2\}$ receive $v_{i 3}$.

In the all-pay auction one equilibrium matches the payoffs of the first winner-pay equilibrium. In this equilibrium player 3 does not actively participate in the bidding and players 1 and 2 randomize uniformly over [0, $\left.r_{12}\right]$. In order to prove that no equilibrium of the all-pay auction can give any player at least as high a payoff as the equilibrium of the winner-pay auction in which player 3 wins with a bid of $r_{i 3}$, it is sufficient to show that neither player 1 nor 2 will ever abstain from bidding in any equilibrium. To see this, suppose, player $i \in\{1,2\}$ bids zero with certainty, then players 3 and $j \in\{1,2\} \backslash\{i\}$ only randomize up to $r_{j 3}=r_{i 3}$, leaving both of them with a chance of winning. Player i's equilibrium payoff is therefore equal to his winning payoff when bidding at some point $y \in\left(r_{i 3}, r_{i j}\right)$ and he could strictly improve that payoff by placing a strictly lower bid $b \in\left(r_{i 3}, y\right)$. With all three players participating in equilibrium it is straightforward to show that the upper bound of the support of each player's strategy is always strictly greater than $r_{i 3}$ and thus all players' equilibrium payoffs will always be lower than those in this winner-pay equilibrium.

In ending this section it is worth noting that the results of both examples 4 and 5 are robust; the environments may be perturbed without changing the relevant rankings of the equilibrium payoffs.

\section{Conclusion}

In this paper we have compared and contrasted the properties of equilibrium in all-pay auctions with identitydependent externalities to those of winner-pay auctions with identity-dependent externalities and standard all-pay 
auctions (in the absence of externalities). In addition to proving the existence of equilibrium in all-pay auctions with identity-dependent externalities, we have provided one important positive result: A necessary and sufficient condition for the existence of equilibria with only two active players (so called, "all-pay auction equilibria"), which yield equilibrium distributions and payoffs to the active players that coincide with the generically unique equilibrium of the associated standard two-player all-pay auction. We thereby provide a robustness result extending the analysis of the standard all-pay auction to "small" identity-dependent externalities.

However, we have also shown that many of the conclusions drawn in the literature regarding equilibrium strategies and payoffs in standard all-pay auctions, and their relation to standard winner-pay auctions, must be modified in the presence of IDE. Based on our findings, it does not appear to be possible to make simple statements about equilibrium payoffs for environments with identity-dependent externalities that are as strong as those appearing in previous treatments of standard all-pay contests with auction contest success functions. This includes the results of Baye et al (1996) for standard all-pay auctions and Siegel (2009) for contests with more general cost functions.

Because deviations from the prescriptions of the theory of standard all-pay auctions hold for open sets of vectors of reaches, and standard all-pay contests represent merely a lower-dimensional subspace of the space of all-pay contests with identity-dependent externalities, our results illustrate the need for careful analysis before making predictions in environments modeled as all-pay auctions.

In fact, one might reasonably argue that many of the environments that have lent themselves to modeling as standard all-pay auctions, such as organizational rent seeking, lobbying, presidential primaries, and innovation or patent races, are actually environments with identity-dependent externalities. Given the ubiquity of these environments, further work in applying and extending our analysis appears a fruitful plan of research.

\section{References}

Albano GL, Matros A (2005) (all) equilibria in a class of bidding games. Economics Letters 87(1):61-66

Alcalde J, Dahm M (2010) Rent seeking and rent dissipation: A neutrality result. Journal of Public Economics 94(1-2):1-7

Aseff J, Chade H (2008) An optimal auction with identity-dependent externalities. The RAND Journal of Economics 39(3):731-746

Baye MR, Kovenock D, de Vries C (1996) The all-pay auction with complete information. Economic Theory 8:291-305

Biran O, Forges F (2011) Core-stable rings in auctions with independent private values. Games and Economic Behavior 73(1):52 - 64

Cornet M (2000) Externalities in a bargaining model of public price announcements and resale. Theory and Decision 49(4):375-393

Esteban J, Ray D (1999) Conflict and distribution. Journal of Economic Theory 87(2):379-415

Funk P (1996) Auctions with interdependent valuations. International Journal of Game Theory 25(1):51-64

Hillman AL, Riley JG (1989) Politically contestable rents and transfers. Economics \& Politics 1(1):17-39

Hoppe HC, Jehiel P, Moldovanu B (2006) License auctions and market structure. Journal of Economics \& Management Strategy 15(2):371396

Jehiel P, Moldovanu B (1995a) Cyclical delay in bargaining with externalities. The Review of Economic Studies 62(4):619-637

Jehiel P, Moldovanu B (1995b) Negative externalities may cause delay in negotiation. Econometrica 63(6):1321-1335

Jehiel P, Moldovanu B (1999) Resale markets and the assignment of property rights. The Review of Economic Studies 66(4):971-991

Jehiel P, Moldovanu B (2006) Allocative and informational externalities in auctions and related mechanisms. In: Blundell R, Newey WK,

Persson T (eds) Advances in Economics and Econometrics: Volume 1: Theory and Applications, Ninth World Congress, vol 1, Cambridge University Press, chap 3

Jehiel P, Moldovanu B, Stacchetti E (1999) Multidimensional mechanism design for auctions with externalities. Journal of Economic Theory 85:258-93

Klose B, Kovenock D (2012) Extremism drives out moderation. CESifo Working Paper Number 3804

Konrad KA (2006) Silent interests and all-pay auctions. International Journal of Industrial Organization 24(4):701-713

Linster BG (1993) A generalized model of rent-seeking behavior. Public choice 77(2):421-435

Monteiro PK, Page Jr FH (2007) Uniform payoff security and Nash equilibrium in compact games. Journal of Economic Theory 134(1):566575

Morath F, Münster J (2008) Private versus complete information in auctions. Economics Letters 101(3):214-216

Prokopovych P, Yannelis NC (2013) On uniform conditions for the existence of mixed strategy equilibria. Kyiv School of Economics, Discussion Paper Number 48, revised version, January, 2013

Reny PJ (2009) Further results on the existence of Nash equilibria in discontinuous games. Mimeo, University of Chicago

Siegel R (2009) All-pay contests. Econometrica 77(1):71-92

Simon LK, Zame WR (1990) Discontinuous games and endogenous sharing rules. Econometrica 58(4):861-872

das Varma G (2002) Standard auctions with identity-dependent externalities. The RAND Journal of Economics 33(4):689-708 
2013

\section{Economic Science Institute Working Papers}

13-09 Branas-Garza, P., Kovarik, J., and Neyse, L. Second-to-Fourth Digit Ratio has a NonMonotonic Impact on Altruism.

13-08 McCarter, M., Samak, A., and Sheremeta, R. Divided Loyalties or Conditional Cooperation? An experimental study of contributions to multiple public goods.

13-07 Gabaix, X., Laibson, D., Li, D., Li, H., Resnick, S., and de Vries, C. The Impact of Competition on Prices with Numerous Firms.

13-06 Sheremeta, R. Overbidding and Heterogeneous Behavior in Contest Experiments.

13-05 Deck, C. and Porter, D. Prediction Markets in the Laboratory.

13-04 Corgnet, B., Hernán-Gonzalez, R., Kujal, P., and Porter, D. The Effect of Earned vs. House Money on Price Bubble Formation in Experimental Asset Markets.

13-03 Sheremeta, R. and Zhang, J. Three-Player Trust Game with Insider Communication.

13-02 McCarter, M. and Sheremeta, R. You Can't Put Old Wine in New Bottles: The Effect of Newcomers on Coordination in Groups.

13-01 Corgnet, B., Hernan-Gonzalez, R., and Rassenti, S. Peer Pressure and Moral Hazard in Teams: Experimental Evidence.

\section{2}

12-31 Thomas, C. An Alternating-Offers Model of Multilateral Negotiations.

12-30 Mago, S., Sheremeta, R. and Yates, A. Best-of-Three Contest Experiments: Strategic versus psychological momentum.

12-29 Bigoni, M., Camera, G. and Casari, M. Strategies of Cooperation and Punishment among $\underline{\text { Students and Clerical Workers. }}$

12-28 Camera, G. and Kim, J. Buyer's Equilibrium with Capacity Constraints and Restricted Mobility: A recursive approach.

12-27 Camera, G., Casari, M., and Bigoni, M. Binding Promises and Cooperation Among Strangers.

12-26 Schniter, E., Shields, T. and Dickhaut, J. Ageism \& Cooperation. 
12-25 Gjerstad, S. and Smith, V. Balance Sheet Crises: Causes, Consequences and Responses.

12-24 Gómez-Miñambres, J., Corgnet, B. and Hernán-Gonzalez, R. Goal Setting and Monetary Incentives: When Large Stakes Are Not Enough.

12-23 Clots-Figueras, I., Hernán González, R., and Kujal, P. Asymmetry and Deception in the Investment Game.

12-22 Dechenaux, E., Kovenock, D. and Sheremeta, R. A Survey of Experimental Research on Contests, All-Pay Auctions and Tournaments.

12-21 Rubin, J. and Sheremeta, R. Principal-Agent Settings with Random Shocks.

12-20 Gómez-Miñambres, J. and Schniter, E. Menu-Dependent Emotions and Self-Control.

12-19 Schniter, E., Sheremeta, R., and Sznycer, D. Building and Rebuilding Trust with Promises and Apologies.

12-18 Shields, T. and Xin, B. Higher-order Beliefs in Simple Trading Models.

12-17 Pfeiffer, G. and Shields, T. Performance-Based Compensation and Firm Value: Experimental evidence.

12-16 Kimbrough, E. and Sheremeta, R. Why Can't We Be Friends? Entitlements, bargaining, and conflict.

12-15 Mago, S., Savikhin, A., and Sheremeta, R. Facing Your Opponents: Social identification and information feedback in contests.

12-14 McCarter, M., Kopelman, S., Turk, T. and Ybarra, C. Too Many Cooks Spoil the Broth: How the tragedy of the anticommons emerges in organizations.

12-13 Chowdhury, S., Sheremeta, R. and Turocy, T. Overdissipation and Convergence in Rent-seeking Experiments: Cost structure and prize allocation rules.

12-12 Bodsky, R., Donato, D., James, K. and Porter, D. Experimental Evidence on the Properties of the California's Cap and Trade Price Containment Reserve.

12-11 Branas-Garza, P., Espin, A. and Exadaktylos, F. Students, Volunteers and Subjects: Experiments on social preferences.

12-10 Klose, B. and Kovenock, D. Extremism Drives Out Moderation.

12-09 Buchanan, J. and Wilson, B. An Experiment on Protecting Intellectual Property.

12-08 Buchanan, J., Gjerstad, S. and Porter, D. Information Effects in Multi-Unit Dutch Auctions. 
12-07 Price, C. and Sheremeta, R. Endowment Origin, Demographic Effects and Individual Preferences in Contests.

12-06 Magoa, S. and Sheremeta, R. Multi-Battle Contests: An experimental study.

12-05 Sheremeta, R. and Shields, T. Do Liars Believe? Beliefs and Other-Regarding Preferences in Sender-Receiver Games.

12-04 Sheremeta, R., Masters, W. and Cason. T. Winner-Take-All and Proportional-Prize Contests: Theory and experimental results.

12-03 Buchanan, J., Gjerstad, S. and Smith, V. There's No Place Like Home.

12-02 Corgnet, B. and Rodriguez-Lara, I. Are you a Good Employee or Simply a Good Guy? Influence Costs and Contract Design.

12-01 Kimbrough, E. and Sheremeta, R. Side-Payments and the Costs of Conflict.

2011

11-20 Cason, T., Savikhin, A. and Sheremeta, R. Behavioral Spillovers in Coordination Games.

11-19 Munro, D. and Rassenti, S. Combinatorial Clock Auctions: Price direction and performance.

11-18 Schniter, E., Sheremeta, R., and Sznycer, D. Restoring Damaged Trust with Promises, Atonement and Apology.

11-17 Brañas-Garza, P., and Proestakis, A. Self-discrimination: A field experiment on obesity.

11-16 Brañas-Garza, P., Bucheli, M., Paz Espinosa, M., and García-Muñoz, T. Moral Cleansing and Moral Licenses: Experimental evidence.

11-15 Caginalp, G., Porter, D., and Hao, L. Asset Market Reactions to News: An experimental study.

11-14 Benito, J., Branas-Garz, P., Penelope Hernandez, P., and Sanchis Llopis, J. Strategic Behavior in Schelling Dynamics: A new result and experimental evidence.

11-13 Chui, M., Porter, D., Rassenti, S. and Smith, V. The Effect of Bidding Information in Ascending Auctions.

11-12 Schniter, E., Sheremeta, R. and Shields, T. Conflicted Minds: Recalibrational emotions following trust-based interaction.

11-11 Pedro Rey-Biel, P., Sheremeta, R. and Uler, N. (Bad) Luck or (Lack of) Effort?: Comparing social sharing norms between US and Europe.

11-10 Deck, C., Porter, D., and Smith, V. Double Bubbles in Assets Markets with Multiple Generations. 
11-09 Kimbrough, E., Sheremeta, R., and Shields, T. Resolving Conflicts by a Random Device.

11-08 Brañas-Garza, P., García-Muñoz, T., and Hernan, R. Cognitive effort in the Beauty Contest Game.

11-07 Grether, D., Porter, D., and Shum, M. Intimidation or Impatience? Jump Bidding in On-line Ascending Automobile Auctions.

11-06 Rietz, T., Schniter, E., Sheremeta, R., and Shields, T. Trust, Reciprocity and Rules.

11-05 Corgnet, B., Hernan-Gonzalez, R., and Rassenti, S. Real Effort, Real Leisure and Real-time Supervision: Incentives and peer pressure in virtual organizations.

11-04 Corgnet, B. and Hernán-González R. Don’t Ask Me If You Will Not Listen: The dilemma of participative decision making.

11-03 Rietz, T., Sheremeta, R., Shields, T., and Smith, V. Transparency, Efficiency and the Distribution of Economic Welfare in Pass-Through Investment Trust Games.

11-02 Corgnet, B., Kujal, P. and Porter, D. The Effect of Reliability, Content and Timing of Public Announcements on Asset Trading Behavior.

11-01 Corgnet, B., Kujal, P. and Porter, D. Reaction to Public Information in Markets: How much does ambiguity matter?

\section{0}

10-23 Sheremeta, R. Perfect-Substitutes, Best-Shot, and Weakest-Link Contests between Groups.

10-22 Mago, S., Sheremeta, R., and Yates, A. Best-of-Three Contests: Experimental evidence.

10-21 Kimbrough, E. and Sheremeta, R. Make Him an Offer He Can't Refuse: Avoiding conflicts through side payments.

10-20 Savikhim, A. and Sheremeta, R. Visibility of Contributions and Cost of Inflation: An experiment on public goods.

10-19 Sheremeta, R. and Shields, T. Do Investors Trust or Simply Gamble?

10-18 Deck, C. and Sheremeta, R. Fight or Flight? Defending Against Sequential Attacks in the Game of Siege.

10-17 Deck, C., Lin, S. and Porter, D. Affecting Policy by Manipulating Prediction Markets: Experimental evidence.

10-16 Deck, C. and Kimbrough, E. Can Markets Save Lives? An Experimental Investigation of a Market for Organ Donations. 
10-15 Deck, C., Lee, J. and Reyes, J. Personality and the Consistency of Risk Taking Behavior: Experimental evidence.

10-14 Deck, C. and Nikiforakis, N. Perfect and Imperfect Real-Time Monitoring in a Minimum-Effort Game.

10-13 Deck, C. and Gu, J. Price Increasing Competition? Experimental Evidence.

10-12 Kovenock, D., Roberson, B., and Sheremeta, R. The Attack and Defense of Weakest-Link Networks.

10-11 Wilson, B., Jaworski, T., Schurter, K. and Smyth, A. An Experimental Economic History of Whalers' Rules of Capture.

10-10 DeScioli, P. and Wilson, B. Mine and Thine: The territorial foundations of human property.

10-09 Cason, T., Masters, W. and Sheremeta, R. Entry into Winner-Take-All and Proportional-Prize Contests: An experimental study.

10-08 Savikhin, A. and Sheremeta, R. Simultaneous Decision-Making in Competitive and Cooperative Environments.

10-07 Chowdhury, S. and Sheremeta, R. A generalized Tullock contest.

10-06 Chowdhury, S. and Sheremeta, R. The Equivalence of Contests.

10-05 Shields, T. Do Analysts Tell the Truth? Do Shareholders Listen? An Experimental Study of Analysts' Forecasts and Shareholder Reaction.

10-04 Lin, S. and Rassenti, S. Are Under- and Over-reaction the Same Matter? A Price Inertia based Account.

10-03 Lin, S. Gradual Information Diffusion and Asset Price Momentum.

10-02 Gjerstad, S. and Smith, V. Household Expenditure Cycles and Economic Cycles, 1920-2010.

10-01 Dickhaut, J., Lin, S., Porter, D. and Smith, V. Durability, Re-trading and Market Performance.

2009

09-11 Hazlett, T., Porter, D., and Smith, V. Radio Spectrum and the Disruptive Clarity OF Ronald Coase.

09-10 Sheremeta, R. Expenditures and Information Disclosure in Two-Stage Political Contests.

09-09 Sheremeta, R. and Zhang, J. Can Groups Solve the Problem of Over-Bidding in Contests?

09-08 Sheremeta, R. and Zhang, J. Multi-Level Trust Game with "Insider" Communication. 
09-07 Price, C. and Sheremeta, R. Endowment Effects in Contests.

09-06 Cason, T., Savikhin, A. and Sheremeta, R. Cooperation Spillovers in Coordination Games.

09-05 Sheremeta, R. Contest Design: An experimental investigation.

09-04 Sheremeta, R. Experimental Comparison of Multi-Stage and One-Stage Contests.

09-03 Smith, A., Skarbek, D., and Wilson, B. Anarchy, Groups, and Conflict: An experiment on the emergence of protective associations.

09-02 Jaworski, T. and Wilson, B. Go West Young Man: Self-selection and endogenous property rights.

09-01 Gjerstad, S. Housing Market Price Tier Movements in an Expansion and Collapse.

\section{8}

08-09 Dickhaut, J., Houser, D., Aimone, J., Tila, D. and Johnson, C. High Stakes Behavior with Low Payoffs: Inducing preferences with Holt-Laury gambles.

08-08 Stecher, J., Shields, T. and Dickhaut, J. Generating Ambiguity in the Laboratory.

08-07 Stecher, J., Lunawat, R., Pronin, K. and Dickhaut, J. Decision Making and Trade without Probabilities.

08-06 Dickhaut, J., Lungu, O., Smith, V., Xin, B. and Rustichini, A. A Neuronal Mechanism of Choice.

08-05 Anctil, R., Dickhaut, J., Johnson, K., and Kanodia, C. Does Information Transparency Decrease Coordination Failure?

08-04 Tila, D. and Porter, D. Group Prediction in Information Markets With and Without Trading Information and Price Manipulation Incentives.

08-03 Thomas, C. and Wilson, B. Horizontal Product Differentiation in Auctions and Multilateral Negotiations.

08-02 Oprea, R., Wilson, B. and Zillante, A. War of Attrition: Evidence from a laboratory experiment on market exit.

08-01 Oprea, R., Porter, D., Hibbert, C., Hanson, R. and Tila, D. Can Manipulators Mislead Prediction Market Observers? 